I N S T I T U T O

$\mathrm{DE}$

M E D I C I N A

T R O P I C A L

$\mathrm{DE}$

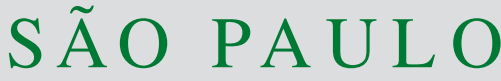

JOURNAL OF THE SÃO PAULO INSTITUTE OF TROPICAL MEDICINE

${ }^{1}$ Secretaria de Estado da Saúde de São Paulo, Coordenadoria de Controle de Doenças, Centro de Vigilância Epidemiológica "Prof. Alexandre Vranjac," Divisão de Doenças de Transmissão Respiratória, São Paulo, São Paulo, Brazil

2Secretaria de Estado da Saúde de São Paulo, Coordenadoria de Controle de Doenças, Instituto Adolfo Lutz, São Paulo, São Paulo, Brazil

Correspondence to: Ana Lucia Frugis Yu Secretaria de Estado da Saúde de São Paulo, Coordenadoria de Controle de Doenças, Centro de Vigilância Epidemiológica "Prof. Alexandre Vranjac", Divisão de Doenças de Transmissão Respiratória, Av. Dr Arnaldo, 351, 6ํandar, Pacaembu, CEP 01246-000, São Paulo, SP, Brazil

Tel.: +55113066 8757

E-mail: alyu@saude.sp.gov.br

Received: 22 April 2021

Accepted: 25 May 2021

\section{SARS-CoV-2 reinfection: report of two cases in Southeast Brazil}

\author{
Ana Lucia Frugis $\mathrm{Yu}^{\circledR}{ }^{\circledR}$, Bernadete L. Liphaus ${ }^{\circledR}$, Patrícia Marques \\ Ferreira ${ }^{\circledR}$, Angela Tiemi Tanamachi ${ }^{\circledR}{ }^{\circledR}$, Eliana Tiemi Masuda ${ }^{\circledR 1}$, \\ Camila Martins Trevisan ${ }^{\circledR}$, Pamella Cristina de Carvalho Lucas ${ }^{\circledR 1}$, \\ Adriana Bugno ${ }^{\circledR 2}$, Telma Regina Marques Pinto Carvalhanas ${ }^{\circledR} 1$
}

\section{ABSTRACT}

From February 26, 2020 to March 11, 2021, coronavirus disease 2019 (COVID-19) pandemic resulted in 11,439,558 cases and 277,102 deaths in Brazil. Among them, 2,195,130 cases and 63,965 deaths occurred in Sao Paulo State, Southeast Brazil. The recent emergence and rise of new variants of SARS-CoV-2 is of concern because of their higher transmissibility and possible association with more severe disease. Cases of SARS-CoV-2 reinfections have been described since December 2020 in Brazil. This report describes two cases of COVID-19 reinfection, that occurred five and six months after the first infection, during the second wave of the pandemic in Sao Paulo State. Both patients presented mild symptoms in the two COVID-19 episodes and different lineages of SARS-CoV-2 were identified: B.1.1.33 and B.1.1.28 lineages in case 1 and B1.1.128 and P. 2 lineages in case 2.

KEYWORDS: COVID-19. SARS-CoV-2. Reinfection. Whole genome sequencing.

\section{INTRODUCTION}

A total of 11,439,558 cases and 277,102 deaths were reported during COVID-19 pandemic, from February 26, 2020 to March 11, 2021, in Brazil. Among them, 2,195,130 cases and 63,965 deaths occurred in Sao Paulo State, Southeast Brazil. COVID-19 cases and deaths had increased again worldwide in November 2020, as well as in Sao Paulo State, that experienced a second wave with more reported cases and deaths than in the first wave ${ }^{1}$.

Serious concerns about SARS-CoV-2 variants have grown during the COVID-19 pandemic evolution. Globally, since the beginning of the pandemic, different SARS-CoV-2 variants have emerged and circulated and viral genomic sequencing and epidemiological investigations are necessary to monitor the emergence and circulation of these variants ${ }^{2,3}$.

The USA Centers for Disease Control and Prevention (CDC) has recently developed a variant classification that defines three classes of SARS-CoV-2 variants: Variants of Interest, Variants of Concern and Variants of High Consequence. Variants of Interest are those associated with increased transmissibility and usually causing surges. Three variants are in this class: B.1.526 and B.1.525, both identified for the first time in the United States and P. 2, first detected in Brazil. Variants of Concern are those related with increased transmissibility and disease severity: B.1.1.7, first detected in the United Kingdom; P. 1, that has emerged in Brazil and has already been detected in several countries; B.1.351 from South Africa, as well as B.1.427 
and B.1.429, both first detected in the United States. Variants of High Consequence cause increased disease severity and greater number of hospitalizations. Their identification requires notification to the World Health Organization (WHO) following the International Health Regulations. Currently, there are no SARS-CoV-2 variants described in this later class ${ }^{4}$.

Health care workers are at increased risk for SARS$\mathrm{CoV}-2$ infections ${ }^{5}$. Frequently, they present with mild or moderate disease or are asymptomatic, although severe disease and death may occur in a smaller proportion of cases $^{5-7}$. From February 26, 2020 to March 11, 741 health care workers developed severe disease and needed hospitalization in Sao Paulo State, mostly physicians (31.9\%) and nursing technicians (28.3\%), according to the nationwide surveillance information system SIVEP-Gripe: Database ${ }^{8}$.

The first SARS-CoV-2 reinfection was confirmed in Hong Kong in August 2020. Two samples from this patient underwent whole genome sequencing. Samples were collected 142 days apart and indicated that SARS-CoV-2 viral genomes belonged to two different lineages. After this report, other similar events were recorded worldwide ${ }^{2,3}$. SARS-CoV-2 reinfection cases have been occurring in Brazil since December 2020, mainly in Rio Grande do Norte, Goias, Minas Gerais, Amazonas and Sao Paulo States'.

The Brazilian epidemiological surveillance adopted the same criteria of the CDC, defining a suspected case of COVID-19 reinfection as two SARS-CoV-2 infections detected by the real-time reverse transcription polymerase chain reaction (RT-PCR) assay, with an interval equal to or greater than 90 days, regardless of the presence of symptoms ${ }^{1}$.

Whole viral genome sequencing was carried out by a Brazilian reference laboratory located at the Instituto Adolfo Lutz (IAL), through the Next Generation Sequencing (NGS) instrument Ion Torrent platform S5 (Thermo Fisher Scientific Inc., Waltham, MA, USA). The obtained strands were processed, evaluated and aligned by IRMA (Interative Refinement Meta-Assembler). The genetic material extracted from the two samples of both cases after RT-PCR using as target, the E gene (envelope protein), N (nucleocapsid protein) and RdRP (RNA - dependent RNA polymerase), in addition to duplicated endogenous human RNAse controls, which enabled the sequencing and the identification of two different lineages. Sequences were deposited by IAL at the Global Initiative on Sharing All Influenza Data - GISAID ${ }^{9}$.

This report describes two SARS-CoV-2 cases among health care workers of Sao Paulo State, with clinical and virological reinfections. Both episodes occurred during the second wave of the pandemic in Sao Paulo State.

\section{CASES REPORT}

Case 1 was a 41-year-old woman with a gastroplasty history, who sought medical attention on 06/24/2020 presenting with headache, myalgia, fatigue, fever, dry cough, shortness of breathe, anosmia and loss of taste, being classified as an influenza-like illness (ILI). The oropharynx swab RT-PCR for SARS-CoV-2 performed on 06/29/2020 resulted positive. As a nursing technician, she reported contact with COVID-19-positive cases. The symptoms lasted seven days. She sought medical attention twice after the first evaluation, and no abnormalities were observed in these two clinical evaluations. The patient remained asymptomatic until 11/17/2020 (146 days after the first episode), when she presented again with the same symptoms, by this time associated with diarrhea, loss of appetite and dizziness. The oropharynx swab RT-PCR for SARS-CoV-2 performed on 11/23/2020 resulted positive. The symptoms lasted about 20 days, without hospitalization, being classified again as an ILI. The whole SARS-CoV-2 genome sequencing of the two samples revealed that the first infection, according to the Pangolin COVID-19 lineage assignment classification ${ }^{10}$, was caused by a B.1.1.33 lineage (GISAID accession No EPI_ISL_708529), while the second one was caused by a B.1.1.28 lineage (GISAID accession $\mathrm{N}^{\circ}$ EPI_ISL_708530) ${ }^{11}$. The D614G spike protein mutation was found in both samples, from the two episodes, and the V1176F spike protein mutation was found in the sample from the second episode. The epidemiological, clinical and laboratory timeline of case 1 reinfection is depicted in Figure 1A.

Case 2, a 34-year-old woman, a nursing technician with a history of chronic respiratory disease, sought medical attention on 08/12/2020 presenting with fever, cough, odynophagia and dyspnea, being classified again as an ILI. The oropharynx swab RT-PCR for SARS-CoV-2 collected on 08/17/2020 resulted positive. On 01/22/2021, the patient received the first dose of a COVID-19 vaccine. On 02/01/2021, 173 days after the first episode and ten days after the vaccination, she presented with headache, running nose, fever and sore throat (ILI). The oropharynx swab RT-PCR for SARS- CoV-2 collected on 02/04/2021, resulted positive. Whole genome sequencing revealed two different strains, according to the Pangolin lineage classification ${ }^{10}$ : B.1.1.28 (GISAID accession $\mathrm{N}^{\circ}$ EPI_ISL_1121326) in the first episode and P. 2 (GISAID accession N N $^{\circ}$ EPI_ISL_1121321) in the second one. The D614G and V1176F spike protein mutations were found in 
(A)

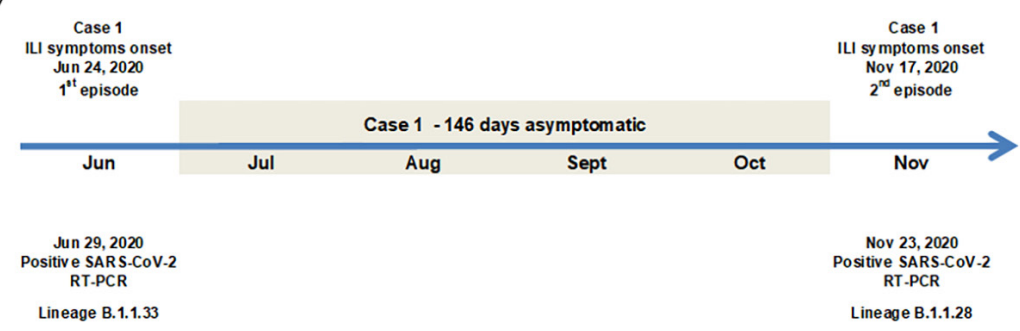

(B)

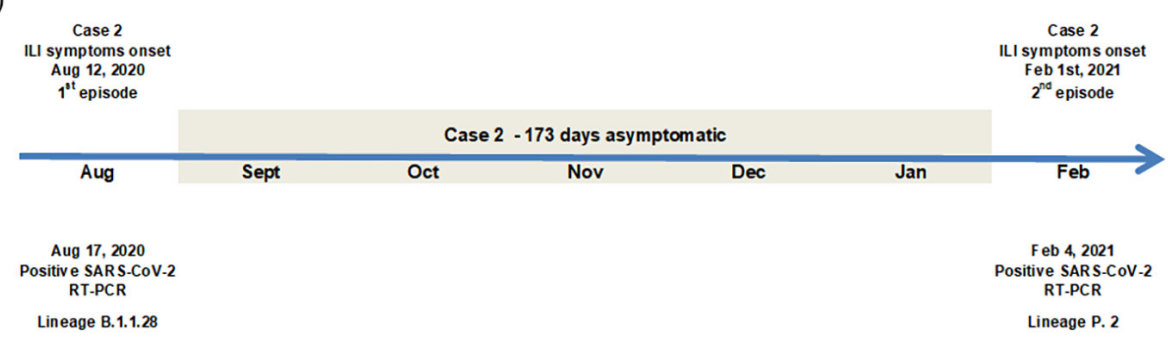

Figure 1 - Epidemiological, clinical and laboratory timeline of case 1 (A) and case 2 (B). ILI = influenza-like illness.

both samples from the two episodes in case 2 and the $\mathrm{E} 484 \mathrm{~K}$ spike protein mutation was found in the second episode only. Case 2 timeline is shown in Figure 1B.

\section{DISCUSSION}

Respiratory viruses' high variability, different genotypes or species, a weak, incomplete or non-lasting immune response may explain the cases of reinfection, including the ones of coronaviruses ${ }^{2,3}$. This report describes two cases of symptomatic COVID-19 and positive RT-PCR five and six months after the first episode, during the second wave of the pandemic in Sao Paulo State, which started in November 2020.

Both patients presented with two episodes of infection and mild symptoms and they were classified as having ILI. Some studies have observed that mild COVID-19 symptoms may indicate a weak and non-lasting immune response to infection ${ }^{2,3}$.

COVID-19 reinfection was confirmed in both cases, since different phylogenetic profiles were identified in each event, 146 and 173 days apart, respectively.

Case 1 presented with the B.1.1.33 lineage in the first episode and the B.1.1.28 lineage in the second one. Both strains were the main lineages that circulated throughout 2020 in the Brazilian Southeast region, where Sao Paulo State is located ${ }^{12}$. Both lineages present with the D614G spike protein mutation that seems to be associated with higher viral load in patients and in animal models, and they are possibly able to infect younger patients more effectively, but it is not associated with more severe COVID-19 and increased mortality ${ }^{13,14}$. In the second episode, the detected lineage presented with the $\mathrm{V} 1176 \mathrm{~F}$ spike protein mutation whose role in COVID-19 remains to be established ${ }^{15}$.

There was a reduction in the identification of B.1.1.33 lineage by the Southeast health surveillance system since September 2020, when the P. 2 lineage identified in the second episode in case 2, was beginning to circulate ${ }^{12}$. The P. 2 variant is classified by the CDC as a Variant of Interest, a sub-clade of B.1.1.28, which harbors the E484K spike protein mutation, associated with immune evasion from neutralizing antibodies. Reinfections associated with the P. 2 variant have been previously reported ${ }^{16,17}$.

Health care workers are at increased risk for SARSCoV-2 infections in comparison with the general population due to the continued exposure to the virus at work. However, few studies evaluated other potential sources of infection, considering the pandemic dynamics and the impact of community-acquired infection ${ }^{5-7}$.

The surveillance of emerging lineages are required and should lead to more epidemiological investigations to assess transmissibility, disease severity, risk of reinfection, improved laboratory characterization and impact on critical SARS-CoV-2 countermeasures, including vaccines ${ }^{4}$.

In conclusion, the identification, frequency and characterization of SARS-CoV-2 reinfection cases may contribute to the pandemic management and control.

\section{ACKNOWLEDGMENTS}

We thank all the Sao Paulo State Epidemiological Surveillance Group (GVE), particularly those who perfomed the case investigation: GVE-XXX and GVE-XV. We also thank the Centro de Vigilancia Epidemiologica 
"Prof. Alexandre Vranjac" (Technical Board and Divisions), Instituto Adolfo Lutz Virology Center and Regional Laboratories, that are involved in the COVID-19 surveillance activities.

\section{AUTHORS' CONTRIBUTIONS}

Concept, first draft and discussion: ALFY, TRMPC. Data collection: BLL, PMF, ATT, ETM, CMT, PCCL, AB. Manuscript elaboration, revision and final version: ALFY, BLL, TRMPC.

\section{REFERENCES}

1. Brasil. Ministério da Saúde. Secretaria de Vigilância em Saúde. Boletim epidemiológico especial: doença pelo Coronavírus COVID-19: boletim epidemiológico especial: semana epidemiológica 11 (14/3 a 20/3/2021). [cited 2021 May 27]. Available from: https://www.gov.br/saude/pt-br/media/ pdf/2021/marco/25/boletim_epidemiologico_covid_55_ atualizado.pdf

2. Yahav D, Yelin D, Eckerle I, Eberhardt CS, Wang J, Cao B, et al. Definitions for coronavirus disease 2019 reinfection, relapse and PCR re-positivity. Clin Microbiol Infect. 2021;27:315-8.

3. Babiker A, Marvil CE, Waggoner JJ, Collins MH, Piantadosi A. The importance and challenges of identifying SARS-CoV-2 reinfections. J Clin Microbiol. 2021;59:e02769-20.

4. Centers for Disease Control and Prevention. SARS-CoV-2 variant classifications and definitions. [cited 2021 May 27]. Available from: https://www.cdc.gov/coronavirus/2019-ncov/casesupdates/variant-surveillance/variant-info.html

5. Gómez-Ochoa SA, Franco OH, Rojas LZ, Raguindin PF, RoaDíaz ZM, Wyssmann BM, et al. COVID-19 in health-care workers: a living systematic review and meta-analysis of prevalence, risk factors, clinical characteristics, and outcomes. Am J Epidemiol. 2021;190:161-75.

6. Iversen K, Bundgaard H, Hasselbalch RB, Kristensen JH, Nielsen PB, Pries-Heje M, et al. Risk of COVID-19 in health-care workers in Denmark: an observational cohort study. Lancet Infect Dis. 2020;20:1401-8.

7. Fernandes Valente Takeda C, Moura de Almeida M, Gonçalves de Aguiar Gomes R, Cisne Souza T, Alves de Lima Mota
M, Pamplona de Góes Cavalcanti L, et al. Recurrent clinical symptoms of COVID-19 in healthcare professionals: a series of cases from Brazil. Am J Trop Med Hyg. 2020;103:1993-6

8. SRAG 2021: Banco de Dados de Síndrome Respiratória Aguda Grave: incluindo dados da COVID-19. [cited 2021 May 27]. Available from: https://opendatasus.saude.gov.br/dataset/bdsrag-2021

9. Camargo CH, Gonçalves CR, Pagnoca EV, Campos KR, Abbud A, Bugno A, et al. Um ano de pandemia da COVID-19: diversidade genética do SARS-CoV-2 no Brasil. Bol Epidemiol Paul. 2021;18:1-33.

10. Rambaut A, Holmes EC, O’Toole A, Hill V, McCrone JT, Ruis $\mathrm{C}$, et al. A dynamic nomenclature proposal for SARS-CoV-2 lineages to assist genomic epidemiology. Nat Microbiol. 2020;5:1403-7.

11. Instituto Adolfo Lutz. COVID-19 em SP: reinfecção. [cited 2021 May 27]. Available from: https://www.ial.sp.gov.br/resources/ insituto-adolfo-lutz/publicacoes/report_4_-_reinfeccao_3.pdf

12. Fundação Oswaldo Cruz. Rede Genômica Fiocruz. [cited 2021 May 27]. Available from: http://www.genomahcov.fiocruz.br

13. Volz E, Hill V, McCrone JT, Price A, Jorgensen D, O'Toole A, et al. Evaluating the effects of SARS-CoV-2 spike mutation D614G on transmissibility and pathogenicity. Cell. 2021;184:64-75. e11.

14. Groves DC, Rowland-Jones SL, Angyal A. The D614G mutations in the SARS-CoV-2 spike protein: implications for viral infectivity, disease severity and vaccine design. Biochem Biophys Res Commun. 2021;538:104-7.

15. Amorim MR, Souza WM, Barros Jr AC, Toledo-Teixeira DA, Dos-Santos KB, Simeoni CL, et al. Respiratory viral shedding in healthcare workers reinfected with SARS-CoV-2, Brazil, 2020. Emerg Infect Dis. 2021;27:1737-40.

16. Resende PC, Gräf T, Paixão AC, Appolinario L, Lopes RS, Mendonça AC, et al. A potential SARS-CoV-2 variant of interest (VOI) harboring mutation $\mathrm{E} 484 \mathrm{~K}$ in the spike protein was identified within lineage B.1.1.33 circulating in Brazil. Viruses. 2021;13:724.

17. Resende PC, Bezerra JF, Teixeira Vasconcelos RH, Arantes I, Appolinario L, Mendonça AC, et al. Severe acute respiratory syndrome Coronavirus 2 P.2 lineage associated with reinfection case, Brazil, June-October 2020. Emerg Infect Dis. 2021 In Press. 